DOI 10.37882/2223-2982.2021.02.29

\title{
РАМОЧНАЯ СТРУКТУРА КАК ОСНОВА КОМПОЗИЦИИ ТЕКСТА ПУБЛИЧНОГО МОНОЛОГА (НА МАТЕРИАЛЕ АНГЛИЙСКОГО ЯЗЫКА)
}

\section{CLOSED-IN CONSTRUCTION AS A BASIS FOR THE TEXT COMPOSITION OF THE PUBLIC MONOLOGUE (A CASE STUDY OF ENGLISH ORATIONS)}

\section{Sviridova}

K. Ulanova

Summary: This article discusses the closed-in construction of a public monologue text, in which the positions of the limiters perform the introduction and the ending, and the core is the medial part containing the message and representing the information intended for the audience. The aim of the research is to analyze the compositional structure of the text of the samples of political, judicial, academic and religious oratory speech belonging to the modern English period. The article focuses on the features of the closed-in construction, within which the semantic part is found, subject to dynamism, which determines the movement from the initial center through the intermediate centers to the final center and, first of all, the sequence of the elements of the content of speech, the composition of speech, the structure and the ratio of its parts. This article also explores the aspects of using etiquette formulae among speech components in the closed-in construction of a public monologue. The relevance of the study is due to modern scientific demands related to the definition of the main structural features in the construction of effective public oratories. The scientific novelty of the research is determined by the need for thorough study of the oratorical text not so much as a unit of oral public speaking, but as an element of speech organization of thought. The article compares the obtained data, summarizes the results of the analysis, and formulates the main results of the study.

Keywords: closed-in construction, oratory, etiquette formulae, public monologue, publicistic style, composition, text, linguistic, discourse, communication, rhetoric.

\author{
Свиридова Лариса Константиновна \\ Д.филол.н., профессор, Московский сочиально- \\ педагогический институт \\ sviridova.l.k@hotmail.com \\ Уланова Капитолина Леонидовна \\ К.филол.н., дочент, Российский университет \\ дружбы народов \\ ulanova-kl@rudn.ru
}

Аннотация: В настоящей статье рассматривается вопрос о рамочной структуре построения текста публичного монолога, в которой позиции ограничителей выполняют зачин и завершение, а ядро представляет собой медиальную часть, содержащую сообщение и представляющую информацию, предназначенную слушателям. Цель исследования - проанализировать построение текста образцов политической, судебной, академической и религиозной ораторской речи, принадлежащей современному английскому периоду. В статье уделяется внимание особенностям структурной рамки, внутри которой обнаруживается смысловая часть, подверженная динамизму, определяющим движение от начального центра через промежуточные центры к конечному центру и в первую очередь, на последовательность расположения элементов содержания речи, на композицию речи, строение и соотношение её частей. Данная статья также исследует характер оформления компонентов речи этикетными формулами в структурной речевой рамке монолога. Актуальность исследования обусловлена современными научными запросами, связанными с определением основных структурных особенностей при построении эффективных публичных выступлений. Научная новизна исследования определяется необходимостью внимательного изучения ораторского текста не столько как единицы устного публичного выступления, сколько как элемента речевой организации мысли. В статье сопоставляются полученные данные, обобщаются результаты анализа, формулируются основные итоги проведённого исследования.

Ключевые слова: рамочная конструкция, ораторская речь, этикетные формулы, публичный монолог, публицистический стиль, композиция, текст, лингвистика, дискурс, коммуникация, риторика.

[2, с.114]. Многие лингвисты уже давно обратили внимание на то, что обязательность употребления готовых языковых формул, их «неприкосновенность» в разговорной речи острее дает себя знать, чем в речи письменной, основанной на процессе обдуманного избирания. Устная речь связана с основной сферой общения людей, в которой с наибольшей отчетливостью проявляется коммуникативная функция языка.

Ораторский стиль речи вызывал интерес ученых на протяжении многих лет, оставаясь актуальным и в настоящее время. К их исследованию обращались В.Н. 
Андреев, Г.З. Апресян, В.В. Виноградов, Т.М. Жуковская, И.А. Зимняя, Н.Н. Кохтев, А.А. Леонтьев, А.К. Михальская, Е.А. Ножин, Ю.В. Рождественский, Е.Н. Сагайдачная, О.Б. Сиротинина, И.С. Тихонова, Е.Л. Фрейдина, Л.С. Чикилева, Н.М. Шанский. Развитие устных форм коммуникации и анализ дискурса как совокупности тематических текстов вызвали необходимость рассмотрения ораторской речи [1, с.232]. Публичное выступление представляет собой одну из важнейших форм речевой деятельности. «Ораторская речь - это речь публичная, то есть обращенная к многочисленной аудитории. В ней особенно усилена такая черта публицистического стиля как направленность на убеждение, воздействие на ум, на чувства слушателей, побуждение их к активным действиям. Ораторская речь отличается особой композицией, использованием определенных выразительных и изобразительных средств» [8, с.234-235]. Смысловая целостность ораторской речи заключается в единстве ее темы, под которой понимается то, что положено в основу, главная мысль речи, основная проблема, поставленная в ней, ее смысловое ядро, и смысловых частей разной структуры и протяженности, которые составляют ее композицию, являющуюся единым целым $[6$, с.135]. Целостность речи связана с рациональной организацией содержащейся в ней информации, что выражается в четком изложении основных идей речи, в конструировании нескольких относительно самостоятельных информационных частей, в последовательном и согласованном их устном изложении, в последовательности переходов от одной мысли к другой. В результате соответствующим образом организованная речь предстает перед слушателями как целостная композиция, в которой каждый смысловой блок занимает свое место. «Композиция речи - это закономерное мотивированное содержанием и замыслом расположения всех частей выступления и целесообразное их соотношение, организация материала, составляющего ее содержание, расположение его по определенной системе» [4, с.43]. По определению Н.Н. Кохтева композиционная структура ораторской речи представляет собой следующую развернутую структуру: 1) зачин, 2) вступление, 3) содержание (главная часть), 4), заключение, 5) концовка. Эта композиционная структура может быть свернутой, что ведет к отсутствию некоторых частей, любой или нескольких, кроме основной содержания. Согласно Е.Л. Фрейдиной, любое речевое произведение, включая устную речь и, естественно, речь ораторскую, имеет начало, середину и конец. Традиционная структура речи включает следующие элементы:

1. вступление, в котором оратор добивается внимания слушателей, знакомит их с темой выступления;

2. основная часть, которая содержит основные идеи, доказательство выдвинутых положений, и

3. заключение (концовка), где происходит краткое повторение основных положений выступления и делаются выводы [7, с.17].
В данном исследовании мы придерживаемся мнения профессора И.Г. Кошевой, что у текста существует определенная структурная рамка типа: «название-заключение» - в письменной, «приветствие-прощание» - в устной речи. Внутри такой структурной рамки обнаруживается смысловая часть, подверженная динамизму, который определяет движение от начального центра через промежуточные центры к конечному центру. Внутренняя наполняемость смысловой части, как ядра рамочной структуры, равна запросу об информации. При этом стилистически запрос может иметь любую выраженность, включая обращение к определенному кругу лиц [5, с.238]. По форме выражения мысли речь распадается на монологическую и диалогическую. Для нас особенно важна форма диалога, причём диалог рассматривается нами как структура, предполагающая обязательное единство трёх составляющих: зачина, ядра и завершения [5, с.241].

Данные компоненты образуют структурную речевую рамку диалога, в котором позиции ограничителей выполняют зачин и завершение, а ядро представляет собой медиальную часть, в которой содержится сообщение. Зачин играет стимулирующую роль для общения, служит установлению контакта для последующего общения. Завершение (заключение) определяет реакцию участников коммуникации на состоявшийся процесс общения и перспективы общения дальнейшего.

Данные компоненты образуют структурную речевую рамку диалога, в котором позиции ограничителей выполняют зачин и завершение, а ядро представляет собой медиальную часть, в которой содержится сообщение, представлена информация, предназначенная слушателям. Зачин играет стимулирующую роль для общения, служит установлению контакта для последующего общения. Завершение (заключение) определяет реакцию участников коммуникации на состоявшийся процесс общения и перспективы общения дальнейшего.

В настоящем исследовании были проанализированы публицистические тексты современного английского периода, относящиеся к политическим, судебным и академическим выступлениям, а также проповедям. Еще В.В. Виноградов обращал внимание на дифференциацию ораторской речи по функциям и по жанрам. Он писал, что «Особый интерес представляют формы ораторской речи, обращенные к многолюдной аудитории или, по крайней мере, рассчитанные на нее, как публичные лекции, религиозные проповеди, речи политические и судебные» [3, с.120-121]. В задачи данного исследования входит рассмотрение вопросов, связанных с определением основных структурных особенностей при построении текста ораторской речи. В ходе исследования использовались методы контекстуального анализа, словарных определений и непрерывной выборки при отборе материала для 
исследования. Теоретическая значимость исследования заключается в том, что оно заполняет пробелы в изучении ораторского искусства, существующие в современной лингвистике; практическая ценность - в возможности использования ее результатов в практике риторики и преподавания ораторского искусства в учебных заведениях различного типа. Целью данного исследования является выявление особенностей построения таких четырех видов ораторской речи, как политическая, судебная, академическая и религиозная.

Речь опытного оратора захватывает слушателей с первых же слов, что часто достигается умелым построением начала речи. Особенности зачина могут определяться темой выступления и аудиторией, и необходимостью привлечения внимания слушателей. Кроме того, в зачине может быть указано, каким образом будет произнесена речь. В семантическом значении зачин может быть связан как с содержанием речи, так и с ситуацией произнесения речи, как в речи Оливера Кромвеля на открытии Парламента (1654г.):

e.g.: "Gentlemen:-You are met here on the greatest occasion, that I believe, England ever saw..." [12]

В содержательном смысле зачин зависит как от информации, представленной в речи, так и от ситуации её произнесения, как в выступлении судьи Стивена Г. Брейера в Национальной комиссии по государственной службе (2002г.):

e.g.: "Mr. Chairman, Members of the National Commission on the Public Service, Although I appreciate your having invited the Chief Justice and me to testify today, I am not very happy to be here. The presence of the Chief Justice of the United States, and my own, suggest that something has gone seriously wrong with the judicial compensation system that the Constitution's Framers foresaw. That system, designed to help secure judicial independence, plays a key role in helping to ensure fair treatment for all Americans and to protect our basic liberties" [11]

Чаще всего ораторское искусство начинается с этикетных формул, например, особенно эмоциональная речь может начинаться с приветствия, с которого выступающий обращается к аудитории, тем самым подчеркивая свое отношение к слушателям, выражая свое отношение к ним, что настраивает их на восприятие определенного стиля речи и служит сигналом к эмоциональному восприятию информации. Например, как в послании «Speech on the Scaffold» Элджернона Сидни (1683г.):

e.g.: "Men, Brethren, and Fathers; Friends, Countrymen and Strangers: - It may be expected that I should now say some great matters unto you ... « [14]

Говоря об особенностях речи, в первую очередь нель- зя не отметить оригинальность, начинающуюся новизну, которая привлекает внимание слушателей, поощряет их в дальнейшем изложении. Эти причины устанавливают два вида контактов между спикером и аудиторией: они используются для психологического контакта и для демонстрации социальных отношений между спикером и слушателями. Например, в проповеди его святейшества Бенедикта XVI в Кофтон парке, Реднал - Бирмингем (2010):

e.g.: "Dear Brothers and Sisters in Christ, This day that has brought us together here in Birmingham is a most auspicious one. In the first place, it is the Lord's day, Sunday, the day when our Lord Jesus Christ rose from the dead and changed the course of human history for ever, offering a new life and hope to all who live in darkness and in the shadow of death." [9]

Зачин является важным элементом ораторской речи, который осмысленно и психологически знакомит слушателя с сутью речи и процессом ее восприятия, что во многом зависит от успешности речи, которая может определять отношение аудитории к говорящему. Чаще всего зачин ярко проявляется в академической речи. Это должно усилить внимание слушателей, привлеченных началом, усилить их интерес. Например, в обращении Томаса Карлайла, лорда-ректора Эдинбургского университета, (1866г.):

e.g.: "YOUR enthusiasm toward me, I must admit, is in itself very beautiful, however undeserved it may be in regard to the object of it. It is a feeling honorable to all men, and one well known to myself when I was of an age like yours, nor is it yet quite gone" [10]

Зачин помогает перейти к основной части (ядру), в которой представлен основной материал. В главной части (содержании) излагается основной материал и используются доказательства, представленные как развернутая цепочка рассуждений. Например, в выступлении судьи Стивена Г. Брейера в Национальной комиссии по государственной службе (2002г.):

e.g.: "A few facts may help explain why I am not overstating. First, the real pay of federal judges has declined dramatically in the past several decades. Between 1969 and 1999 real pay for federal trial court and appellate court judges has declined by about 25\%; during the same period of time, the real pay of the average American worker increased by $12.4 \%$. [...] Second, the salaries of top executives in large non-profit organizations are now significantly higher than those of federal judges. As you can see, the average nonprofit CEO's salary as of three years ago was about $20 \%$ higher than that of a Supreme Court Justice and about 35\% higher than that of a federal district judge. [...] Finally, for completeness, I have made a few foreign comparisons. As you can see, increases in judicial compensation in Canada 
and Great Britain have far exceeded 4 the increases in the cost of living in those countries in recent years, while in the United States the opposite is true" [11]

В конце выступления можно подвести итоги, завершить и обобщить те мысли, которые были высказаны в основной части выступления. Возможно, краткое повторение основных пунктов речи или объединение ее отдельных частей, также может подчеркнуть основную идею выступления и важность для слушателей разобранной темы. Кроме того, в завершении намечаются пути развития идей, высказанных спикером, и эмоционально передается содержание всей речи. Важно закрепить и усилить впечатление, производимое содержанием речи, поставить на основе всей речи перед аудиторией какие-либо задачи. Что касается завершения, то оно может содержать этикетные формулы, формулы призыва, пожелания, сообщения о чем-то, не имеющем прямого отношения к содержанию речи. Часто завершение составляет сильную единицу. Варианты завершения могут быть разными и зависят от многих факторов: темы, материала, времени, аудитории, типа и вида речи. Как уже отмечалось, форма завершения зависит от вида красноречия и цель речи. Проповедь, университетская лекция, политическая речь или судебный монолог заканчиваются по-разному, что диктуется определенными внутренними законами публичной речи. Например,

- в проповеди его святейшества Бенедикта XVI в Кофтон парке, Реднал - Бирмингем (2010г.):

e.g.: "What better way to express the joy of this moment than by turning to our heavenly Father in heartfelt thanksgiving, praying in the words that Blessed John Henry Newman placed on the lips of the choirs of angels in heaven..." [9]

- в монологе "My defence against impeachment" To- маса Уэнтуорта, графа Страффорд, в палате Лордов (1641г.):

e.g.: "My lords! My lords! My lords! Something more I had intended to say, but my voice and my spirit fail me." [15]

- в выступлении судьи Стивена Г. Брейера в Национальной комиссии по государственной службе (2002г.):

e.g.: "Again, I appreciate the opportunity to address this issue. And I am happy to answer any questions. Thank you." [11]

- в академической лекции «As the Literary Guest of America" Чарльза Диккенса, произнесенной на ужине, устроенном в его честь (1842):

e.g.: "But these are topics familiar from my boyhood, and which I am apt to pursue; and lest I should be tempted now to talk too long about them, I will, in conclusion, give you a sentiment, most appropriate..." [13]

Таким образом, в результате комплексного рассмотрения особенностей построения политической, академической, судебной и религиозной ораторской речи, необходимо отметить, что, являясь закономерным, мотивированным содержанием и замыслом, структурная организация речи - композиция состоит из следующих смысловых частей (зачина, медиальной части - содержания и завершения), которые имеют свои функции и свое строение, вступают в связь с другими частями ораторской речи. Кроме того, различные виды ораторской речи имеют в разной степени обусловленную композицию, что связано с целью и ситуацией речи. Размер, продолжительность рамочных элементов речи могут быть разными в зависимости от ряда условий произнесения речи: её темы, общей продолжительности, особенностей аудитории, вида речи.

ЛИТЕРАТУРА

1. Бурая Е.А., Галочкина И.Е., Шевченко Т.И. Фонетика современного английского языка. - М.: Издательский центр «Академия», 2009. - 272 с.

2. Вандриес Ж. Язык. Лингвистическое введение в историю. - М.: Едиториал УРСС, 2010 - 410с.

3. Виноградов В.В. Избранные труды. 0 языке художественной прозы. - М.: Наука, 1980. - 366 с.

4. Кохтев Н.Н. Ораторская речь: стиль и композиция. - М.: Изд-во МГУ, 1992. - 176 с.

5. Кошевая И.Г. Стилистика современного английского языка. - М.: Издательский центр «Академия», 2011. - 352 с.

6. Уланова К.Л. Композиционно-стилистические аспекты построения ораторской речи (на материале английского языка) / К.Л. Уланова // Научное мнение. СПб: Санкт-Петербургский университетский консорциум, 2015. №11. С. $134-137$.

7. Фрейдина Е.Л., Самохина Т.С., Тихонова И.С., Ковалева Л.Б., Михайлова А.В. Основы публичной речи: Learning to Speak in Public. - Дубна: Феникс+, 2007. - 136 с.

8. Шанский Н.М. Этимологический словарь русского языка. Т. ІІ. Вып. VIII. - М.: Изд-во Московский университет, 1982. - Т. II. Вып. VIII. К. - 471 с.

9. Benedict XVI Mass with the beatification of Venerable Cardinal John Henry Newman, 2010. [Электронный ресурc] URL: https://w2.vatican.va/content/benedictxvi/en/homilies/2010/documents/hf_ben-xvi_hom_20100919_beatif-newman.html (Дата обращения 24.02.2019)

10. Carlyle Thomas Address as Lord Rector of Edinburgh University, 1866. [Электронный ресурc] URL: https://www.bartleby.com/268/5/2.html (Дата обращения 24.12.2018)

11. Breyer Stephen G. Statement at National Commission on the Public Service, 2002. [Электронный ресурc] URL: https://www.supremecourt.gov/publicinfo/speeches/ ncps_project.pdf (Дата обращения 20.02.2019) 
12. Cromwell Oliver Opening of Parliament Under the Protectorate, 1654. [Электронный ресурc] URL:http://www.strecorsoc.org/docs/cromwell.html (Дата 0бращения 24.02.2019)

13. Dickens Charles As the Literary Guest of America, 1842. [Электронный ресурc] URL: https://www.bartleby.com/268/4/15.html (Дата 0бращения 21.01.2019)

14. Sidney Algernon Speech on the Scaffold, 1683. [Электронный ресурc] URL: https://www.bartleby.com/268/3/14.html (Дата 0бращения 04.03.2019)

(с) Свиридова Лариса Константиновна (sviridova.l.k@hotmail.com), Уланова Капитолина Леонидовна (ulanova-kl@rudn.ru).

Журнал «Современная наука: актуальные проблемы теории и практики»

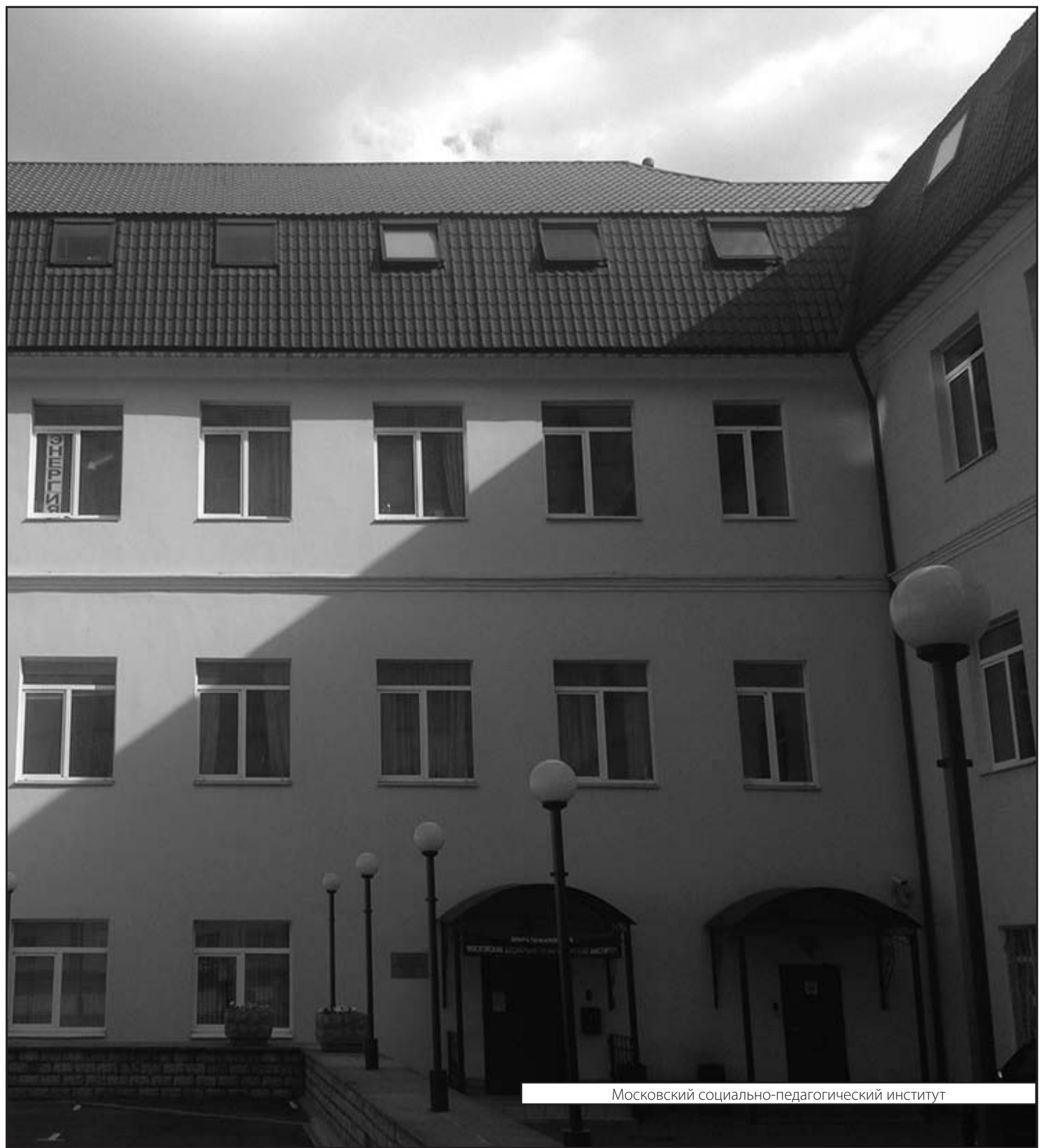

